\title{
Da intencionalidade da consciência ao método progressivo regressivo em Husserl
}

\author{
Thiago Gomes de Castro ${ }^{*}$ \\ William Barbosa Gomes ${ }^{\text {b }}$ \\ aPontifícia Universidade Católica do Rio Grande do Sul, Faculdade de Psicologia. Porto Alegre, RS, Brasi \\ bUniversidade Federal do Rio Grande do Sul, Instituto de Psicologia. Porto Alegre, RS, Brasil
}

Resumo: 0 artigo analisa a natureza cognitiva e fenomenológica da consciência, iniciando pelas condições fenomenais e concluindo pelas atividades proposicionais cognitivas. Seu objetivo é apontar limites e potenciais do método fenomenológico. Assim, examinam-se os conceitos de fluxo de vivência, modelo intencional de fluxo, e veracidade da autoevidência para especificar o problema do método. Argumenta-se que a atividade reflexiva é limitada, não sendo capaz de abarcar o conjunto flutuante de significados e vivências em suas margens no fluxo. Lida-se com os limites atentando-se para os dois movimentos reflexivos: 1) o progressivo que conduz à descrição pontual e exaustiva dos elementos estáticos e noemáticos da experiência; e 2) o regressivo que explora as origens, expectativas, potencialidades e falhas da atividade intencional. Conclui-se que o método fenomenológico, apesar dos limites, é recurso valioso para orientar o pesquisador em como pensar (condição noética, genética, egoica, regressiva) o próprio pensamento (condição noemática, estática, conteudística, progressiva).

Palavras-chave: fenomenologia, método, consciência, sínteses perceptivas.

A fenomenologia durante boa parte do século XX esteve fortemente associada ao existencialismo e assim se tornou muito conhecida e referenciada por psicólogos e psicoterapeutas humanistas. No entanto, nas últimas duas décadas o interesse pela teoria fenomenológica de Husserl tem crescido com relevância no âmbito das ciências cognitivas e por decorrência no próprio campo da Filosofia. Assim, torna-se oportuno rever elementos do caminho percorrido por Husserl entre a intencionalidade da consciência até a definição das sínteses ativas e passivas no fluxo de vividos. Oportuno especialmente em razão das reformulações que o filósofo empreendeu em seu método fenomenológico na década de 1920 e que repercutem diretamente na possibilidade ou não de uma naturalização da fenomenologia. As considerações que serão apresentadas a essas definições estão baseadas na obra de Husserl, inclusive publicações póstumas, e na interpretação de comentaristas, referenciados ao longo do texto. Com esse retorno a Husserl, resgata-se um intrigante e precursor entendimento operativo da consciência e agrega subsídios à prática da análise fenomenológica progressiva e regressiva. Estes subsídios estão na diferenciação entre a compreensão imediata dos objetos da experiência e a busca pela gênese dos modos experienciais consolidados em vieses intencionais. A diferenciação é crucial para a realização de pesquisas qualitativas fenomenológicas e para a escuta clínica fenomenológica.

A presente exposição está organizada em três partes. A primeira trata do fluxo de vivências como experiência consciente, destacando sua condição unitária, presentificada e retencional. A segunda distingue os processos de

*Autor correspondente: thiago.cast@gmail.com síntese ativa e passiva na emergência da intencionalidade da consciência: a síntese ativa, decorrente da mudança atencional e da orientação do fluxo da consciência; e a síntese passiva que se refere ao acúmulo experiencial como confronto subjacente à consciência do novo. A terceira aborda a tão decantada descrição fenomenológica para diferenciar os objetos dados à experiência consciente como constituintes estáticos (fenomenologia estática), e a exploração dos emergentes explícitos e implícitos na consciência da experiência ao longo do tempo como constituintes históricos (fenomenologia genética). Por conclusão, apontam-se contribuições, problemas e equívocos com relação à teoria, ao método e à evidência fenomenológica. Entre a atividade consciente e o método para estudá-la despontam problemas sobre o que tomar como evidência e como gerenciar a exploração lógica. Mesmo que Husserl não tenha elucidado a questão de modo empírico, seus avanços fornecem bases sólidas para métodos e procedimentos fenomenológicos aplicados à filosofia, à ciência e à clínica psicológica.

\section{Intencionalidade, fluxo e experiência consciente}

$\mathrm{Na}$ fenomenologia, o estudo do movimento ativo intencional de pensar um objeto é denominado ciência noética. Em contrapartida, o estudo do objeto estático pensado no pensamento caracteriza o viés da chamada ciência noemática (Husserl, 1901/2001). Sob essa distinção, o fenomenólogo Edmund Husserl entende a intencionalidade da consciência como distintivamente operante (Merleau-Ponty, 1945/1999), que é pré-reflexiva e que transita entre puro fluxo (Noese) e momentos reflexivos sobre o fluxo (Noema). O conjunto de significados 
operando sobre novas evidências experienciais é denominado de percepção (Husserl, 1973/1997). Nesse contexto inicial da obra do filósofo, o objetivo do estudo da fenomenologia era o contraste entre as lógicas de movimento noético intencional, e a descrição da composição essencial dos elementos estáticos consagrados no campo experiencial perceptivo.

A ideia de fluxo de vivências de Husserl foi influenciada pela definição de fluxo de pensamentos de William James (1842-1910) e intencionalidade de Franz Brentano (1838-1917) (Jacob, 2010). No caso de James, Husserl substituiu pensamento por vivência, mas a noção de fluxo é muito semelhante (Figura 1). De acordo com Perrin (2004), a noção de James sobre o presente ilusório (specious present) informa a concepção de fluxo de Husserl acerca da existência única do presente na experiência. As recordações seriam, nesse sentido, imagens no presente, resgatadas à luz do horizonte das intenções. Contudo, para Perin (2004), Husserl rompe com a concepção de fluxo de James quando tenta livrar o fluxo de todo e qualquer resíduo psicológico da consciência para buscar a essência estrita da dinâmica do fluxo. Por essa razão Husserl prefere falar de vividos e não de pensamentos, pois em um fluxo de pensamentos a constituição da experiência ocorreria como em um trilho de pensamentos consecutivos. Nesse caso, a análise do fluxo seria realizada por meio de inferências conscientes (resíduos psicológicos) sobre a lógica da articulação entre os pensamentos, numa espécie de naturalização ou conceptualização externa à experiência própria do fluxo. A experiência própria intencional do fluxo é o foco de Husserl.

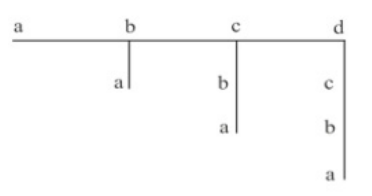

Intencionalidade Brentano

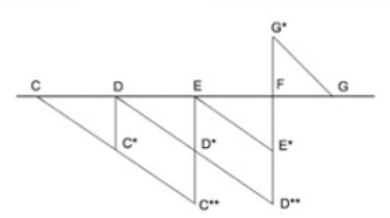

Fluxo de Vivências de Husserl

Figura 1. Origem do modelo de fluxo de Husserl. Fluxos adaptados de Gallagher (2005)

Na Figura 1 constamos que cada pensamento de James é fruto de articulações de outras experiências que imbricadas informam o pensamento no presente ilusório. Já no modelo de Husserl as letras "C", "D" e "E" indicam eventos concretos no passado, enquanto os asteriscos sobre as mesmas letras referem à retomada imagética dessas experiências no presente "F". A retomada das experiências (retenções) ocorre à luz da experiência presente "F" (impressão primária) e do horizonte intencional " $\mathrm{G}$ " (protenções) sobre um futuro ainda não ocorrido " $G$ ".
É importante frisar que a noção de fluxo de James se opõe às teses associacionistas sobre o processo mental, em que o pensamento é entendido como uma composição de elementos independentes semelhantes a átomos da percepção (Bertoni \& Pinto, 2007). A noção de tempo nas teses associacionistas seria descontínua, mesmo que linear, em uma sequência de elementos independentes. Para James (1890/1952), o pensamento é contínuo em forma de fluxo, sendo que um evento de experiência é afetado pelos anteriores, imediatamente afetando os eventos experienciais seguintes. A transição entre um pensamento e outro não teria para James uma interrupção sensível, mas seria contínuo o que apontaria para uma unidade da experiência consciente no fluxo (specious present). Contrastes repentinos na qualidade da percepção não configurariam uma quebra do fluxo, mas apenas a apresentação de cenários sensíveis diferentes que serão integrados na experiência presente.

Nessa direção, a fenomenologia de James refere-se ao estudo da experiência pura consciente e imediata no que se convencionou denominar Empirismo radical (Taylor, 2010). No Empirismo radical a derivação do conhecimento sobre as coisas encontra seu fundamento tão somente na experiência das coisas. O sentido significativo da experiência total é adquirido tanto nas particularidades de cada experiência como também nas relações entre as experiências, muitas vezes aparentemente desconectadas do ponto de vista reflexivo. O interesse desse autor pela experiência imediata revela a mesma preocupação de Husserl com a subjetividade transcendental, sendo que James inclusive trata o Empirismo radical como o estudo de estados transcendentais, ou da experiência pura na indiferenciação entre sujeito e objeto no presente (James, 1912/2003).

Segundo Taylor (2010), Husserl acessou o texto de James pelo amigo em comum Carl Stumpf (1848-1936). Stumpf e James se encontraram apenas duas vezes na Europa, a primeira vez em Praga em 1882 e depois em Munique em 1892. Próximo ao segundo encontro foi quando James enviou uma cópia do Principles of Psychology para Stumpf (Dazzi, 1994). Além disso, mantiveram intensa troca de correspondências ao longo dos anos. Husserl teria lido o Principles of Psychology (1890) na década de 1890, tendo o obtido por meio de Stumpf.

A influência da intencionalidade de Brentano, por sua vez, indica a direcionalidade da consciência para um objeto, e o peso das experiências anteriores na composição da objetividade imanente dos fenômenos atuais na consciência. Husserl, todavia, não concorda que os objetos intencionados sejam imanentes ao ato psicológico, isto é, criados no ato intencional (Jacob, 2010). Para Husserl, ainda que os objetos intencionados no presente sejam influenciados pela direcionalidade consciente configurada no passado do fluxo, sempre ocorrerão novas impressões primárias. Husserl concorda com uma direcionalidade prévia dos atos intencionais, mas afirma que a influência das experiências passadas se define pelo modo como a experiência atual acessa tal passado (retenções). A Figura 1 indica com clareza a diferença entre o modelo de Brentano 
sobre a composição mais diretiva do fluxo e o modelo de Husserl que apresenta possíveis reconfigurações do acesso às experiências passadas (asteriscos) pela visada da experiência atual.

Para Husserl a recalibração da intencionalidade no presente não interfere diretamente e conscientemente na pré-direcionalidade do fluxo, mas informa o acesso ao passado e os momentos de consciência seguintes. As retenções são os resquícios de impressões primárias da percepção em momentos anteriores, retomadas à luz do novo acesso experiencial no presente - novas impressões primárias - e que são articuladas com as protenções no horizonte intencional. Trata-se, portanto, de uma estrutura temporal tripla no fluxo de vivências: retenções-impressões primárias-protenções (van Gelder, 1999).

Diferentemente de Brentano, na formulação Husserliana há espaço para os elementos de expectativa do fluxo, que influenciam a experiência do presente, mas que não estão conscientemente vislumbrados no ato (Husserl, 1928/2000). A redefinição da intencionalidade de Brentano por Husserl desviou a interpretação da experiência consciente como um ato derivado restritamente aos elementos consagrados no fluxo. Para Brentano, as experiências passadas tinham peso decisivo na direcionalidade dos atos atuais da consciência. Contudo, a ideia de experiências consagradas no fluxo desagrada Husserl, que entende a visada do passado como um recurso disperso no tempo e não diretamente direcionador da experiência atual. A implicação metodológica dessa mudança é que Husserl entendeu que o fluxo não poderia ser estudado pela Psicologia descritiva estrita, como propunha Brentano, uma vez que os atos da consciência não são derivativos de experiências consagradas, mas da fusão da estrutura temporal tripla do fluxo. O fluxo transcende as retenções, principalmente em razão da estrutura dispersa da consciência do tempo (Durgin \& Sternberg, 2002). Daí a dificuldade de uma descrição plena.

A ênfase de Husserl recairá no estudo fenomenológico da intencionalidade via redução fenomenológica, que será a suspensão dos resíduos da consciência para se ater à dispersão do fluxo no tempo - subjetividade transcendental
(DeCastro \& Gomes, 2011; Husserl, 1913/2006). Até meados da década de 1910, Husserl desenvolverá seu método fenomenológico em torno das reduções fenomenológicas. A Tabela 1 depura as definições de redução nesse período.

Para Oliveira e Zilio (2006), Brentano e Husserl são autores importantes na discussão sobre a temporalidade da consciência porque abordam precisamente a questão da duração do momento presente na consciência. Os modelos de fluxo de Brentano, James e Husserl são oponentes à noção linear, aditiva e estática da recepção de estímulos pelo aparato sensorial, como observado no modelo de fluxo do filósofo britânico Herbert Spencer (1820-1903). Como é possível observar na ilustração (Figura 2), a relação entre a passagem de tempo e o processamento dos estímulos não acarreta o sequenciamento constitutivo de uma consciência ou intencionalidade operante, mas a recepção e reação isolada a diferentes estímulos providos pelo ambiente. No modelo de Spencer prevalece a ideia de que a realidade é evidenciada pela persistência da consciência a estímulos estáticos em sequência linear temporal (Leslie, 2006). Há pouco espaço à atividade constitutiva consciente em modelos do século XIX derivados de fisiologia cerebral.

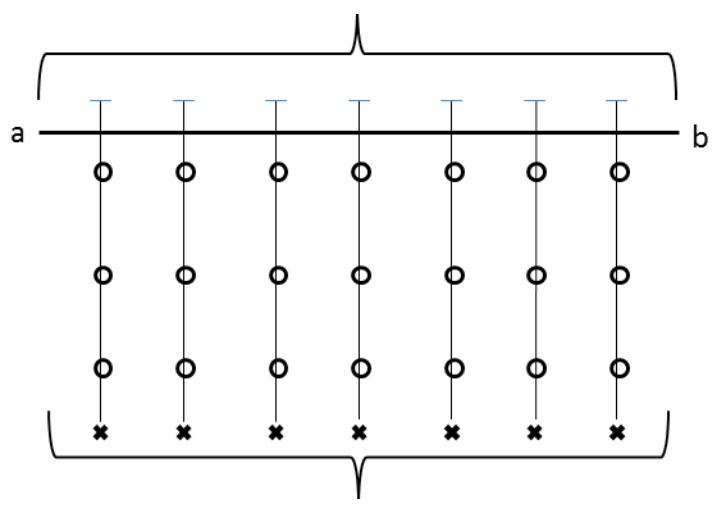

Figura 2. Modelo de fluxo de Herbert Spencer

Na fase inicial da obra de Husserl a relação entre intencionalidade e experiência aparece mediada pela grande ênfase dada à reflexão consciente. Nesse momento, o autor

Tabela 1

Reduções fenomenológicas / Husserl 1907\#; 1913*

\begin{tabular}{|c|c|c|}
\hline Reduções & Definição & Finalidade \\
\hline $\begin{array}{l}\text { Redução Fenomenológica - } \\
\text { Princípio \#* }\end{array}$ & $\begin{array}{l}\text { Recurso para a exclusão do transcendente à } \\
\text { consciência e subsequente observação da constituição } \\
\text { dos objetos da percepção. }\end{array}$ & $\begin{array}{l}\text { Descrição da evidência pura à consciência e } \\
\text { investigação das essências expressivas. }\end{array}$ \\
\hline $\begin{array}{l}\text { Redução Fenomenológica } \\
\text { Psicológica* }\end{array}$ & $\begin{array}{l}\text { Atitude de suspensão das teses valorativas do mundo } \\
\text { natural. }\end{array}$ & $\begin{array}{l}\text { Descrição das significações próprias do } \\
\text { sujeito empírico. }\end{array}$ \\
\hline Redução Eidética* & $\begin{array}{l}\text { Análise intuitiva das essências da evidência perceptiva } \\
\text { - adoção do procedimento de Variação Imaginativa } \\
\text { Livre. }\end{array}$ & $\begin{array}{l}\text { Captação do sentido elementar e definidor } \\
\text { da essência da vivência perceptiva na } \\
\text { subjetividade. }\end{array}$ \\
\hline $\begin{array}{l}\text { Redução fenomenológica } \\
\text { transcendental* }\end{array}$ & $\begin{array}{l}\text { Suspensão do sujeito empírico e do mundo } \\
\text { circundante. }\end{array}$ & $\begin{array}{l}\text { Compreender de forma universal o } \\
\text { movimento puro intencional da consciência. }\end{array}$ \\
\hline
\end{tabular}


está interessado nas articulações da percepção através das evidências disponibilizadas pela reflexividade no fluxo. Isto é, o entendimento da percepção pelo que se faz acessível ao campo da consciência reflexiva. A percepção possui aí um caráter vinculado às operações lógicas de doação de significado. No entanto, a lógica reflexiva é incapaz de apreender os elementos não refletidos, mas presentes no fluxo de vivências. Tal limitação exigiu um novo entendimento do fluxo, que é a sua constituição por sínteses ativas e passivas. Contudo, antes de passar às formulações sobre as sínteses, cabe situar a proposição de Husserl em alguns modelos temporais de consciência na Filosofia.

De acordo com Dainton (2010), existem três modelos básicos de estrutura da consciência temporal identificados na história da Filosofia. São eles o modelo retencional de temporalidade, o modelo extensional e o modelo cinemático (Figura 3). A proposta de consciência temporal de Husserl encaixa-se no modelo retencional, pois sustenta que os conteúdos da experiência do momento presente aparecem unitariamente sob variações de modos temporais de presentação (Figura 3, modo A). Nesse sentido, ainda que ocorra identificação dos elementos no fluxo em sua sequencia de composição para a geração da experiência imediata, eles são experienciados unitariamente como um elemento só. São retidos no tempo para compor a experiência do presente. Mesmo assim, os elementos não são experienciados como tendo a mesma imediatidão fenomenal, mas possuem um sentido de unidade transiente no tempo. Segundo Dainton (2010), os episódios de consciência ocorrem nesse modelo segundo uma relação entre fases momentâneas de experiência imediata e representações do passado recente. $\mathrm{O}$ fluxo de consciência é composto nesse caso pela sucessão desses estados momentâneos.

Além de Husserl, outros teóricos identificados ao modelo retencional de consciência temporal foram Kant, Brentano e William James. As motivações dos teóricos em aderir a esse modelo circulam em torno da tese das representações anteriores na composição da experiência imediata. Portanto, experiências temporais, como mudança e persistência, são derivadas da combinação de dois fatores: uma fase momentânea da experiência presente e uma apreensão simultânea de reproduções ou retenções de experiências recém-ocorridas. Essa tese oferece uma explicação simples e intuitiva, por exemplo, para a diferenciação entre a experiência de sucessão e a sucessão de experiências. No primeiro caso, a experiência de sucessão, os conteúdos compondo a sucessão são apresentados conjuntamente, como um todo, para um único momento de consciência. Já na sucessão de experiências, ocorre um sequenciamento em blocos de eventos experienciais, mais ao modo do modelo extensional de consciência de tempo.

De acordo com Dainton (2010), outra motivação explícita para a aderência ao modelo retencional é a tese de Santo Agostinho sobre o Presentismo, segundo a qual não existe passado ou futuro, mas apenas o presente. Para o modelo retencional a explicação sobre persistência perceptiva e transição de consciência revela-se no presente

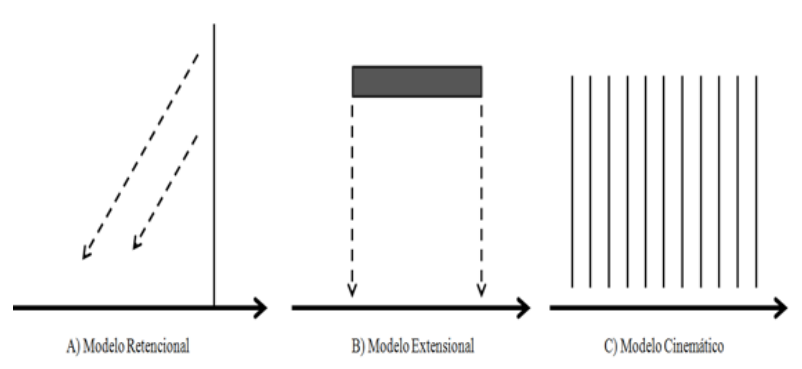

Figura 3. Modelos de consciência do tempo. Modelos adaptados de Dainton (2010)

da experiência que se utiliza de retenções ou protenções, mas nunca reafirma a realidade do passado ou futuro experiencial como evidência concreta do presente. No caso de Husserl, a composição temporal da experiência do presente é também mediada pelos atos perceptuais. Ou seja, pela ação do horizonte intencional, ou visada do fenômeno. Nesse caso, as retenções e protenções não ocorrem diretamente aos objetos da consciência, mas são mediadas pelos atos intencionais que resgatam e remontam os objetos ao campo experiencial do presente conforme seu horizonte.

O modelo extensional, em contrapartida, permite o entendimento de que nossos episódios de consciência são individualmente estendidos no tempo. Não ocorrem por sucessão de episódios atemporais que levam à sensação de temporalidade e unidade experiencial, como no modelo retencional. No modelo extensional, o presente experiencial é dado pela simultaneidade de eventos conscientes ocorrendo de modo estendido no tempo (Figura 3, modo B). A sequência de eventos conscientes na extensão é apresentada por episódios distintos de consciência e não por superposição de retenções e protenções em um mesmo episódio consciente. Mesmo assim os modelos retencional e extensional podem ser convergentes. William James é um exemplo de como os modelos podem estar integrados, sendo sua noção de fluxo uma versão híbrida. James trabalha com uma noção de blocos de pensamento em sequência não linear (Kinouchi, 2004), o que se alinha ao modelo extensional, mas reconhece o impacto das retenções no fluxo.

O modelo cinemático, por sua vez, define o fluxo temporal consciente como uma sucessão contínua de estados momentâneos de consciência. Nessa proposição a consciência imediata carece de qualquer extensão temporal do evento consciente. Além disso, nesse modelo, os conteúdos dos quais somos diretamente conscientes são estáticos. Conforme Dainton (2010), os eventos conscientes são análogos aos filmes, que consistem de uma sequencia rápida de imagens estáticas (Figura 3, modo C). Ou seja, os eventos estão conectados, mas apenas pela sua ordem de sequenciamento estático no tempo. Um dos proponentes do modelo cinemático de consciência do tempo foi o filósofo 
britânico Thomas Reid (1710-1796). Comparando-se o modelo cinemático com o fluxo linear de Spencer (Figura 2) constatamos tratar-se do mesmo modelo.

Embora as reflexões sobre os modelos de consciência do tempo auxiliem a identificar concepções de fluxo e experiência consciente em diferentes teóricos, é tarefa árdua situar autores contemporâneos e achados experimentais sobre consciência do tempo em apenas uma dessas categorias. Mesmo no modelo husserliano de consciência do tempo, a lógica retencional para a composição do presente é dificultada quando contrastamos tal definição com sua teoria sobre sínteses ativas e passivas na consciência. Husserl indica momentos de pura atividade reflexiva na composição das retenções, mas também momentos não reflexivos que auxiliam na composição passiva do campo experiencial.

Vejamos na seção seguinte como o autor define a composição do campo experiencial e a gênese do fluxo de vivências pela alternância entre atividade e passividade do ego.

\section{Intencionalidade e sínteses ativas e passivas}

A noção de síntese para Husserl (1966/2001) se distingue em duas modalidades determinantes do sentido emergente da intencionalidade. A síntese ativa se define pela mudança atencional entre um tema refletido e outro no contínuo do fluxo. Os derivados do confronto da migração atencional estão entre as experiências acumuladas e a atividade genuína do ego em seu momento de execução. Em contraste, a síntese passiva é consciência do sentimento/afecção que domina a relação de identificação do objeto intencionado com o campo consagrado do fluxo. A consciência aí é a de familiaridade. O passivo está no senso constante do acúmulo experiencial que confronta a consciência de novos objetos e não é orientado por movimentos atencionais/reflexivos. Ainda assim, para Husserl (1966/2001), a atividade atencional do fluxo modula a fundação da passividade nas associações das impressões no decorrer do fluxo. A síntese ativa fornece nexo e significado às associações das sínteses passivas, em um movimento de retroalimentação atividade-passividade.

As implicações das sínteses para a lógica reflexiva estão na apreensão e julgamento da novidade que se apresenta em um dado momento real. Assim, a formação da consciência (lógica reflexiva) se sustenta e complexifica por duas qualidades: 1) assimilação contígua de objetos por meio de identificação no fluxo de experiências (retenções e protenções), e 2) atividades predicativas ou de julgamento que são derivadas da mudança atentiva, ou seja, da atitude natural para a atitude fenomenológica. Por atitude natural entendem-se os sentidos oriundos de objetos que estão presentes à consciência fornecidos pelas retenções e protenções. Já a atitude fenomenológica no fluxo seria a operação consciente superior que identifica os traços genéticos constituintes dos padrões imutáveis no fluxo das vivências.
Essa mudança atentiva caracteriza o alcance egoico da atividade, e é o modo constante pelo qual a consciência se desvela para a atividade em progresso: "toda a atividade genuína é realizada no escopo da atentividade" (Husserl, 1966/2001, p. 276).

Embora Husserl mencione o termo "ego" como atividade no fluxo de vivências, sua teoria inicial do fluxo é não egológica. De acordo com Zahavi (2005), não há para Husserl nenhum polo egoico puro compartilhado por todas as experiências e que condicione a unidade dessas experiências. Husserl (1901/2001) reconhece apenas dois usos legítimos do termo ego em sua Quinta Investigação Lógica. Ou o ego é simplesmente idêntico ao indivíduo empírico, ao qual acessamos por suas características de terceira pessoa, por exemplo, nacionalidade, profissão, gênero e altura. Ou o termo ego é usado como sinônimo de fluxo de vivências. No caso de ego como fluxo, o ego não é um princípio formal de identidade, mas a impressão que reúne as experiências em sua totalidade. Assim, a relação entre uma experiência única e o ego é analisável em termos de uma relação parte-todo (Zahavi, 2005). Para Husserl (1901/2001), o ego fenomenológico não é nada mais do que a totalidade de um complexo de experiências.

A descrição do fluxo de experiências, como analisado nos parágrafos anteriores, revela a centralidade da atenção para Husserl nos desdobramentos da atividade no fluxo. Como foi abordado, Husserl refere alta relevância ao monitoramento consciente no curso das retenções e protenções para a significação das experiências presentes. Essa dependência no movimento atencional do fluxo foi posteriormente avaliada por Aron Gurwitsch (1901-1973) como um ponto de conflito entre a teoria fenomenológica de Husserl e as proposições experimentais sobre atenção entre os Gestaltistas (Arvidson, 2006). De acordo com Gurwitsch (1964), Husserl não fez distinção entre os conceitos tema (I), margens perceptivas (II) e contexto temático (III). Tema seria a ideia de que a consciência se ocupa reflexivamente de algum conteúdo. Margem seriam os itens não tematizados no fluxo. Contexto temático seria a reunião de elementos refletidos e não refletidos no fluxo. No entanto, Arvidson (2006) pontua que talvez Gurwitsch não tenha tido acesso ao texto póstumo de Husserl "Análise sobre sínteses ativas e passivas" que aborda o tema das margens perceptivas pela via da síntese passiva. O texto abrange uma série de conferências ministradas por Husserl na Universidade de Friburgo entre os anos 1920 e 1926, tendo sido publicado em alemão pela primeira vez apenas em 1966 e em inglês em 2001.

Segundo Gurwitsch (1964), as análises intencionais de Husserl se restringiam à observação dos temas da consciência em contextos sequenciais de experiência baseados em familiaridade ou intuições de expectativas na protenção. Todavia, não abarcavam o resíduo perceptivo na transição de experiência não tematizada pela consciência. A análise de Gurwitsch (1966) indica que Husserl contempla, mas não analisa detidamente tais resíduos. Desconsiderando, por conseguinte, os efeitos da causalidade de contextos de 
tematização não refletidos no fluxo, mas demarcadores de efeitos proposicionais na intencionalidade. Esses efeitos não refletidos no fluxo e componentes dos diferentes contextos criariam as margens perceptivas sob as quais as novas atividades conscientes estabeleceriam sua orientação ideacional e propositiva.

Este é o argumento que compõe a tese da Gestalt, de que a atenção não seria uma atividade exclusiva de foco consciente, mas sim uma atividade proposicional do aparato cognitivo não restrito ao foco ou elementos tematizados na consciência. Arvidson (2006) entende que Husserl abordou a distinção entre tema e margem perceptiva pela relevância ou irrelevância do tema na presença ou ausência da atividade do fluxo, mas não desenvolveu suficientemente essa distinção. A saída, como relatado anteriormente, poderia estar na síntese passiva, pois a centralidade da atividade atentiva do fluxo ainda não seria preponderante aí. Mesmo assim, Husserl indica que qualquer síntese do fluxo anterior à atenção orienta-se pelo ponto de vista noético. A síntese passiva poderia ser uma via, pois a distinção entre os temas ocorreria aí por gradientes de vivacidade experiencial e por princípios de organização inerente aos noemas, mas não por reflexividade. Contudo, conforme Arvidson, Husserl não deixa dúvidas que mesmo na interconexão entre temáticas e resíduos irrelevantes (margens) o que prevalece é o exercício da atenção por meio de julgamentos que levam à síntese, sempre expandindo a unidade da experiência consciente.

De acordo com Gurwitsch (1966), a ênfase do cogito husserliano é a correlação dominada pela noeses, isto é, da intenção com o tema, na sustentação do tema ao longo do tempo em um foco consciente. Desse modo, o tema permanece presente, mesmo não sendo atual. A funcionalidade do cogito está em trazer ao presente como atualidade algo não atual (retenções). A atividade recai na reflexão consciente dos temas nessa presentificação de inatualidades e protenções. $\mathrm{O}$ cogito parece estar subscrito nesse momento à atividade de tematização para Husserl em uma análise estática (eidética) desse fluxo. Por outro lado, como veremos adiante, uma análise genética seria necessária e recairia sobre o processo histórico de constituição das sínteses no fluxo (Husserl, 1966/2001).

Para Gurwitsch (1966) as inatualidades pertencem ao contexto temático, mas não ao tema presente explícito. Nesse sentido a retomada de temas a partir do contexto temático, ou horizonte experiencial, remete a uma noção de vivacidade da experiência, e não de demarcações de distinção entre consciência da experiência e não consciência da experiência. Já para Husserl, segundo Gurwitsch, as inatualidades pertencem ao tema, revivência consciente e afetiva das experiências, mas não ao contexto temático e suas margens não reflexivas. Tratase, em última instância, de uma discussão sobre o lugar e importância da reflexão na composição do fluxo consciente de vividos.

$\mathrm{Na}$ análise de Arvidson (2006), Gurwitsch não aceita a concepção reflexiva-consciente de atenção
Husserliana. A concepção de atenção em Gurwitsch é a de campo temático não explícito em conteúdos conscientes. Tal formulação o aproxima das Ciências Cognitivas contemporâneas, que separam a atividade consciente da atividade atentiva, mas as consideram como processos complementares. Gurwitsch (1966) propõe uma análise do fluxo baseada nas regularidades e sustentações de um tema no fluxo, e, portanto, enfatiza o contexto temático ao qual se subjaz a atividade consciente.

Na visão de Gurwitsch (1966), trazer algo à atenção (grasping) designa a atividade de voltar atenção a um tema, àquilo que se transforma em tema. Por outro lado, manter ao longo do tempo esse tema no campo consciente refere-se à regularidade experiencial do tema que, uma vez já tematizado, é agora dado como componente do contexto temático. A correlação entre inatualidades e atualidades, nesse caso, não ocorre por identificação de semelhanças (associações conscientes), mas por construção inevitável de tendências nem sempre semelhantes no fluxo. São elementos aditivos acidentais, e não retomados apenas por uma lógica de compatibilidade aparente. Para Gurwitsch (1966), Husserl perde a noção de transformação de um elemento quando ele é tomado a cada novo passo judicativo. A ocupação com tematizações em Husserl ocorreria por atividade atentiva reflexiva e propositiva, enquanto as assimilações em um contexto temático seriam acidentais, pois não teriam monitoramento constante da consciência.

Para Husserl, uma vez liberado um conteúdo da consciência ele permanece no campo experiencial, como retenção, mas é agora irrelevante ao tema. Para Gurwitsch esse conteúdo é ainda relevante, pois permanece como margem e define novas tendências intencionais. Husserl (1966/2001) atribui a diferenciação entre contexto temático e margem pela atividade consciente, por isso dificilmente encontra-se clareza na proposição, uma vez que não ocorre tal atividade na margem. Gurwitsch quer atribuir essa diferenciação a partir de princípios de organização de estruturas invariáveis no fluxo, ao que denomina campo da consciência ao contrário de atividade consciente. Analisaremos na seção seguinte como o entendimento de fluxo de vivências e a descrição da experiência consciente definem conexões com o método genético e estático da fenomenologia de Husserl.

\section{Método genético e estático \& descrição fenomenológica}

Conforme Husserl (1901/2001), os significados que tomam vida na experiência não devem se satisfazer com uma compreensão verbal meramente simbólica, pautada em intuições remotas, confusas e impróprias da linguagem natural. O filósofo propõe o exercício da compreensão de significados pela realização intuitiva da abstração na experiência autorreflexiva e comunicativa. Na etapa descritiva da fenomenologia, Husserl entende que a descrição experiencial só faria sentido se investigada no próprio contexto da realização da experiência consciente tematizada. 
A fenomenologia descritiva das Investigações lógicas supõe que a interpretação, como recurso lógico da compreensão, tem de ser levada a cabo no próprio momento de ocorrência do ato de expressão (Husserl, 1901/2001). Sendo, portanto, intuitiva por reconhecer a limitação da expressão como tradução da experiência consciente. A abstração intuitiva, nesses termos, ocorre sobre a evidência do campo experiencial, e a lógica de articulação para a compreensão desse campo se utiliza dos elementos descritivos oferecidos. A manutenção dessa disposição intuitiva leva ao que Husserl chama de identidade da análise fenomenológica. Nesse período, o autor define: "A fenomenologia das vivências lógicas tem por fim proporcionar uma compreensão descritiva das vivências psíquicas e do sentido implícito nelas" (Husserl, 1901/2001, p. 219).

Em relação à posição da descrição na consolidação do método fenomenológico, Husserl apresenta dois momentos distintos. O primeiro conceito de descrição está bem consolidado em seu texto de 1901, e refere-se ao que Husserl posteriormente denominará de inquérito fenomenológico estático. O segundo momento de destaque da descrição está presente em uma série de textos compilados na década de 1920 (Husserl, 1966/2001) e é nomeado inquérito fenomenológico genético. Nos dois casos a importância da descrição para o inquérito se justifica pela complementariedade entre estático e genético na compreensão da correlação consciência-experiência.

$\mathrm{Na}$ descrição da fenomenologia estática, apesar de se reconhecer a volatilidade da linguagem, a lógica de inquirição se fundamenta em uma abstração formal do fluxo consciente em sínteses de impressões, retenções e protenções com base na linguagem da experiência vivida ${ }^{2}$. A formalização do fluxo permite, nesse momento, a definição do inquérito descritivo com base em elementos estáticos ou essenciais (redução eidética) da experiência e também nas disposições de abertura expressiva (qualidades estáticas dos modos de abertura à experiência). A lógica da síntese descritiva se efetiva no instante da consciência da experiência e implica uma análise das retenções do passado experiencial e das protenções ao futuro derivadas do fluxo. Em outros termos, a descrição obedece aí uma ordem progressiva que orienta a compreensão da experiência consciente aos elementos estáticos da expressão da linguagem no presente (Steinbock, 2001).

Em contrapartida, a descrição no inquérito fenomenológico genético contempla a ideia de que o fluxo consciente ocorre de modo estável e, portanto, pode supor uma unidade egoica que transcende linearmente o passado em direção ao futuro (Husserl, 1966/2001). Nessa orientação, a experiência consciente seria derivada da sedimentação histórica de disposições intencionais, conscientes e não conscientes, do campo perceptivo. $\mathrm{O}$ inquérito descritivo, por conseguinte, se encaminharia aqui a um sentido regressivo, buscando a gênese dos modos experienciais consolidados

2 Ver Husserl (1928/2000) Vorlesungen zur Phänomenologie des inneren zeitbewußtseins. em vieses intencionais (gênese monádica - individuação experiencial) (Steinbock, 2001).

A modificação entre os dois inquéritos revela-se, na verdade, uma modificação na compreensão da ontologia fenomenológica. O indivíduo, nesse segundo momento, é a fonte da temporalização e, portanto, medida da gênese intencional. Não está contido na formalização do fluxo temporal, como aparenta nas primeiras definições de consciência do tempo. Aliás, a primeira correlação fenomenológica consciência-experiência abre brechas para os critérios lógicos estáticos criticados por Husserl nas ciências naturais. Contudo, o filósofo não abandona o modelo progressivo do inquérito descritivo, mas o incorpora em um sistema metodológico mais abrangente. Além de promover uma investigação progressiva das disposições de abertura descritiva até as essencialidades experienciais será também necessário levar a cabo a via regressiva (Husserl, 1966/2001). Na via regressiva genética, partindo das estruturas essenciais de manifestação ou das unidades de análise naturalizadas por convenção científica, buscase, em um segundo momento, percorrer o caminho inverso. Algo como se o modo progressivo de identificação de unidades essenciais da experiência consciente fosse submetido à análise secundária crítica da constituição do percurso intencional que levou até as unidades. Em suma, a constituição estática se torna pista para a investigação das gêneses, tanto lógica (epistemologia) quanto intencional (ontologia da percepção).

A mudança concreta no inquérito, entre esses dois períodos, ocorre quando se permite incluir elementos que não estão sendo enunciados necessariamente no presente. Ou seja, a descrição deixa de se pautar apenas em sínteses intencionais da fala no presente. O inquérito descritivo passa a suscitar a expressão em diversos sentidos temporais e em diferentes contextos, com o intuito de se chegar a uma compreensão ampla e histórica da constituição dos modos atuais de intenção na percepção. $\mathrm{O}$ inquérito genético clássico se aproxima a um modelo de naturalização da fenomenologia, citado por Zahavi (2010), no que tange à análise das lógicas inferenciais que compõe a gênese da compreensão do empírico em uma pesquisa. A via regressiva genética é propícia para a compreensão do desenvolvimento de um fenômeno psicológico em uma base histórica formal de constituição, além de reinserir as sínteses passivas não tematizadas no fluxo consciente para a análise plena da intencionalidade.

\section{Considerações finais}

O grande interesse e o reconhecimento das implicações das ciências cognitivas para a teoria do conhecimento e para a epistemologia estimularam um debate rico e promissor entre filosofia da mente e fenomenologia. Para o campo de estudos fenomenológicos, foco deste artigo, as implicações decorrentes foram importantes, pois trouxeram ao debate a teoria fenomenológica de Husserl, e ressaltaram os elementos cognitivos implícitos à teoria tais como 
retenção e protenção. Em termos cognitivos, Husserl assumiu, em sua teoria, o modelo de fluxo retencional, e como James, de certo modo o fluxo extensional. Assim, a intencionalidade é influenciada, no seu percurso significativo, por sínteses ativas, aquelas engendradas na instantaneidade das vivências, e por sínteses passivas, aquelas formadas na história dos vividos e direcionadoras das expectativas e horizontes experienciais. Neste ponto, a funcionalidade e a estrutura da consciência impõem um impasse entre o livre fluxo intencional das vivências e o limitante monitoramento egoico. Nota-se que o ego se refere ao fluxo intencional e ao ato noético, ou seja, a transição entre pré-reflexão e reflexão.

Embora o uso do método tenha sobrepujado o conhecimento da teoria, é importante considerar os insights teóricos da fenomenologia em relação à atividade e à estrutura da consciência em cuja base se propõe o método. Caso contrário, o método se reduz a um arranjo taxonômico de descrições, e ainda agregando restrições anedóticas às fontes vivenciais do pesquisador. $\mathrm{O}$ método fenomenológico não pode ser considerado como um controle que se impõe ao que se observa ou a quem se entrevista. Não é, portanto, um procedimento de terceira pessoa. Trata-se de um encontro intersubjetivo entre primeiras pessoas, sendo que as rigorosas exigências do método servem para o pesquisador como primeira pessoa e para o inquiridor e não, para o colaborador participante. Há que se preservar a liberdade de exploração e de campo experiencial. Seja qual forem as fontes de informação, os dados se apresentam ao pesquisador como capta (compreensão, interpretação), e neste sentido as suas condições perceptuais exercem, simultaneamente, as funções de ato (o sujeito que percebe) e objeto (o que se percebe). Nesta correlação, entre ato-objeto, consciência-experiência, noese-noema, atua o vínculo intencional e as estruturas que sustentam, clarificam, e deformam o percepto. Nesta mesma correlação está a força do método: o reconhecimento de suas falhas e limites bem como de seus recursos e refinamentos. Como falhas e limites estão as distorções decorrentes do monitoramento egoico. Como recursos e refinamentos estão os procedimentos sistemáticos e imbricados na descrição, redução e interpretação, considerando as movimentações reflexivas entre progressão, que focaliza o material estático; e regressão, que focaliza o material genético.
A análise apresentada neste texto contemplou duas categorias de debates teóricos com relação à fenomenologia e por extensão às teorias em geral. A primeira se refere ao trabalho de Husserl nas reformulações de conceitos propostos por seus antecessores. No caso, as reformulações para conceitos como intencionalidade, emprestado de Brentano, e fluxo emprestado de James. A segunda se refere às reformulações posteriores oferecidas por estudiosos $\mathrm{e}$ simpatizantes da teoria, como exemplificado no debate entre Gurwitsch $(1964,1966)$ e Arvidson (2006). Este argumentou que as inovações de Gurwitsch estavam, de certo modo, contempladas nos estudos sobre as sínteses ativas e passivas de Husserl (1966/2001). No entanto, reconhecemse duas importantes contribuições de Gurwitsch: 1) ir além da teoria, abrindo diálogo com teóricos contemporâneos, no caso com a Psicologia da Gestalt, um exemplo a ser seguido; e 2) avançar a teoria introduzindo princípios gestálticos, como campo temático e campo marginal. Gurwitsch trabalhou com Husserl em 1922, sendo que as Sínteses foram escritas entre 1920 e 1926 (Spiegelberg, 1982).

Estudos contemporâneos sobre a consciência favorecem a diferenciação entre atenção e atividade consciente, e a prática do método fenomenológico recomenda cuidado rigoroso com a análise do movimento entre tema, margens perceptivas e contexto temático. Esses são os ingredientes do fluxo e tropeços à atividade atencional reflexiva. A riqueza do método fenomenológico está justamente na articulação entre o tema, suas margens presentes e ausentes, e sua hermenêutica. Essas seriam as bases para uma interpretação fenomenológica perspicaz, instigante, justa, e inovadora, mas é também a flexibilidade e a incerteza que torna o método complexo e possibilista.

Críticas à viabilidade do projeto fenomenológico husserliano não são incomuns. De um lado, encontra-se a resistência do autor em finalizar uma ideia metodológica que saia do terreno de filosofia primeira e das considerações transcendentais antinaturalistas. De outro, a profusão de interesses do texto husserliano deixou uma herança polivalente aos estudiosos da fenomenologia no século XX, sendo inclusive tarefa difícil delimitar uma psicologia fenomenológica a partir dessas heranças. Nesse cenário, ainda ocorre resistência à opção pela confluência entre literatura fenomenológica e a pesquisa científica, em grande parte oriunda do próprio campo fenomenológico e não da comunidade científica em geral.

\section{From intentional consciousness to progressive regressive method in Husserl}

Abstract: The paper examines the cognitive and phenomenological nature of consciousness, starting with the phenomenal conditions and concluding by its cognitive dispositional activities. The goal is to point out the limits and potentials of the phenomenological method. Thus, we examine the concepts of flow of experience, intentional flow model, and accuracy of self-evidence to specify the problem of method. It is argued that the reflexive activity is limited, not being able to cover the whole floating of meanings and experiences in its margins in the flow. It deals with the limits paying attention to two reflexive movements: 1) the progressive leading to timely and exhaustive description of static elements of experience, and 2) the regressive exploring the origins, expectations, and potential failures of the 
intentional activity. We conclude that the phenomenological method, despite its limitations, is a valuable resource to guide the researcher in how to think the thought itself.

Keywords: phenomenology, method, consciousness, perceptual syntheses.

\section{Desde la intencionalidad de la conciencia al método progresivo regresivo en Husserl}

Resumen: Este artículo examina la naturaleza cognitiva y fenomenológica de la conciencia, empieza por las condiciones fenomenales y concluye en sus actividades proposicionales cognitivas. Su objetivo es señalar los límites y potencialidades del método fenomenológico. Por lo tanto, se examinan los conceptos de flujo de experiencias, modelo de flujo intencional, y la exactitud de la auto evidencia para especificar el problema del método. Se argumenta que la actividad reflexiva es limitada, pues no es capaz de cubrir todo el flotante de significados y experiencias en sus márgenes en el flujo. Se abordan los límites a partir de dos movimientos reflexivos: 1) el progresivo que conduce a la descripción puntual y exhaustiva de elementos estáticos y neomáticos de la experiencia, y 2) el regresivo que explora los orígenes, expectativas y posibles fracasos de la actividad intencional. Se concluye que el método fenomenológico, a pesar de sus limitaciones, es un recurso valioso para guiar al investigador en la forma de pensar (condición noética, genética, egoica, regresiva) el propio pensamiento (condición noemática, estática, del contenido, progresiva).

Palabras-clave: fenomenología, método, consciencia, síntesis perceptivas.

\section{De l'intentionnalité de la conscience à le méthode progressif régressif de Husserl}

Résumé: Dans cet article, est analysée la nature cognitive et phénoménologique de la conscience, en partant des conditions phénoménales et tout en concluantles activités aux attitudes cognitives. L'objectif est de souligner les limites et les potentialités de la méthode phénoménologique. Ainsi, sont examinésles concepts de flux de l'expérience, de modèle de flux intentionnel et la précision de l'évidence, dans le but despécifier le problème de la méthode. On fait valoir que l'activité réflexive est limitée,n'étant pas en mesure de couvrir l'ensemble variable de significations et d'expériences en ses marges dans le flux. On se penche sur les limites avec attention sur les deux mouvements réflexes: 1 ) le progressif, qui conduit à la description rapide et exhaustive des éléments statiques d'expérience ; 2 ) le régressif, qui explore les origines, les attentes et les échecs éventuels de l'activité intentionnelle. Il est conclu que la méthode phénoménologique, malgré ses limites, est une ressource précieuse pour guider le chercheur dans la façon de penser (condition noétique, génétique, égoïque, régressif) la pensée elle-même (condition noématique, statique, contenudistique, progressif).

Mots-clés: phénoménologie, méthode, conscience, synthèses perceptives.

\section{Referências}

Arvidson, P. S. (2006). The sphere of attention: context and margin. Dordrecht, Netherlands: Springer.

Bertoni, P. G., \& Pinto, D. C. M. (2007). Mudança e continuidade: a formulação Jamesiana do pensamento como um fluxo. Psicologia: Reflexão \& Crítica, 20(2), 205-211.

Dainton, B. (2010). Temporal consciousness. In E. N. Zalta (Ed.), The Stanford Encyclopedia of Philosophy. Recuperado de: http://plato.stanford.edu/archives/ fall2010/entries/temporal-consciousness

Dazzi, N. (1994). James and Stumpf: Similarities and Differences. Psychologie und Geschichte, 6(3-4), 244-257.

DeCastro, T. G., \& Gomes, W. B. (2011). Movimento Fenomenológico: Controvérsias e Perspectivas na Pesquisa Psicológica. Psicologia: Teoria e Pesquisa, 27(2), 233-240.
Durgin, F. H., \& Sternberg, S. (2002). The time of consciousness and vice versa. Consciousness \& Cognition, 11(2), 284-290.

Gallagher, S. (2005). How the body shapes the mind. York, NY: Oxford University Press.

Gurwitsch, A. (1964). The field of consciousness. Pittsburgh, PA: Duquesne University Press.

Gurwitsch, A. (1966). Studies in phenomenology and psychology. Evanston, IL: Northwestern University Press.

Husserl, E. (1997). Thing and Space: Lectures of 1907. Netherlands: Kluwer Academic Publisher. (Trabalho original publicado em 1973)

Husserl, E. (2000). Vorlesungen zur Phänomenologie des inneren zeitbewußtseins. [Palestras sobre a fenomenologia da consciência interna do tempo.] Tübingen: Max Niemeyer. (Trabalho original publicado em 1928) 
Husserl, E. (2001). Analyses concerning passive and active synthesis: lectures on transcendental logic (A. J. Steinbock, trans.). Dordrecht, Netherlands: Kluwer Academic Publishers. (Trabalho original publicado em 1966)

Husserl, E. (2001). Logical Investigations. Florence: Routledge. (Trabalho original publicado em 1901).

Husserl, E. (2006). Ideias para uma fenomenologia pura e para uma filosofia fenomenológica. São Paulo: Ideias \& Letras. (Trabalho original publicado em 1913)

Jacob, P. (2010). Intentionality. In E. N. Zalta (Ed.), The Stanford Encyclopedia of Philosophy. Recuperado de http://plato.stanford.edu/archives/fall2010/entries/ intentionality/>.

James, W. (1952). The principles of psychology. In: Britannica great books of the western world. Chicago, IL: Chicago University Press. (Trabalho original publicado em 1890)

James, W. (2003). Essays in radical empiricism. Mineola, NY: Dover Publications. (Trabalho original publicado em 1912)

Leslie, J. C. (2006). Herbert Spencer's contributions to behavior analysis: a retrospective review of Principles of Psychology. Journal of the Experimental Analysis of Behavior, 86(1), 123-129.

Kinouchi, R. R. (2004). Consciência não linear: de William James aos sistemas dinâmicos (Tese de doutorado). Programa de Pós-graduação em Filosofia, Universidade Federal de São Carlos, São Carlos, SP.

Merleau-Ponty, M. (1999). Fenomenologia da percepção. São Paulo, SP: Martins Fontes (Trabalho original publicado em 1945)
Oliveira, C. M., \& Zilio, D. (2006). A experiência subjetiva do tempo em Husserl e Brentano: contribuições das neurociências. Ciências \& Cognição, 8, 110-117.

Perrin, D. (2004). Husserl e Wittgenstein leitores de James: a questão do tempo. Dois Pontos, 1(1), 59-97.

Spiegelberg, H. (1982). The phenomenological movement. The Hague: Martinus Nijhoff.

Steinbock, A. J. (2001). Translator's introduction. In E. Husserl, Analyses concerning passive and active synthesis (pp. 15-65). Dordrecht, Netherlands: Kluwer Academic Publishers.

Taylor, E. (2010). Could radical empiricism guide neurophenomenology as the future of neuroscience? Toward a science of consciousness, 9, 68-69.

Van Gelder, T. (1999). Wooden iron? Husserlian phenomenology meets cognitive science. In J. Petitot, F. Varela, B. Pachoud, \& J.-M. Roy (Eds.), Naturalizing Phenomenology: Issues in contemporary Phenomenology and Cognitive Sciences (pp. 245-265). Stanford, CA: Stanford University Press.

Zahavi, D. (2005). Subjectivity and selfhood: investigating the first-person perspective. Cambridge, MA: The MIT Press.

Zahavi, D. (2010). Naturalized Phenomenology. In S. Gallagher \& D. Schmicking (Eds.), Handbook of Phenomenology and Cognitive Science (pp. 1-12). Netherlands: Springer.
Recebido: $10 / 09 / 2013$

Revisado: 22/04/2014

Aceito: 03/10/2014 